\title{
PENERAPAN SELF-ESTEEM DALAM PEMBELAJARAN MATEMATIKA MENGGUNAKAN PENDEKATAN OPEN-ENDED
}

\author{
Novika Andriani A. Jariah' ${ }^{1}$ Zulkardi $^{2}$, Yusuf Hartono ${ }^{3}$ \\ ${ }^{1}$ Mahasiswa FKIP Universitas Sriwijaya \\ ${ }^{2,3}$ Dosen FKIP Universitas Sriwijaya \\ E-mail:novikaaaj@gmail.com
}

\begin{abstract}
ABSTRAK
Penelitian ini merupakan penelitian deskriptif yang bertujuan untuk memperoleh deskripsi mengenai self-esteem siswa dalam pembelajaran matematika menggunakan pendekatan open-ended. Subjek dari penelitian ini yaitu siswa kelas VIII.6 SMP Negeri 2 OKU yang berjumlah 42 orang. Proses pembelajaran berlangsung sesuai dengan tahapan pembelajaran pada pendekatan open-ended. Teknik pengumpulan data yakni dengan menggunakan angket MSSE (Math-Spesific Self-esteem), lembar observasi MBCSE (Metcalfe Behavioural Checklist of Selfesteem), dan wawancara. Berdasarkan hasil penelitian, self-esteem siswa dalam pembelajaran matematika menggunakan pendekatan open-ended adalah tinggi. Hal ini dilihat dari hasil perolehan angket MSSE dan lembar observasi MBCSE, yaitu dengan rincian sebagai berikut: dari data lembar observasi MBCSE persentase siswa yang memiliki self-esteem dengan kategori sangat tinggi adalah 7,1\%. Selanjutnya 56\% siswa dengan kategori self-esteem tinggi; 36,9\% siswa dengan kategori self-esteem rendah. Sementara, berdasarkan data angket MSSE persentase siswa dengan kategori self-esteem sangat tinggi adalah 30\% dan $70 \%$ siswa dengan kategori self-esteem tinggi.
\end{abstract}

Kata kunci: Self-esteem, pembelajaran matematika, pendekatan open-ended.

\section{PENDAHULUAN}

Bloom menyatakan bahwa tujuan pembelajaran terbagi dalam 3 domain, yakni kognitif, afektif, dan psikomotorik (Randall, 2011). Dikarenakan hal inilah, hendaknya pembelajaran bukan hanya memfasilitasi siswa dalam ranah kognitif, melainkan juga pada ranah afektif. Fenomena pada afektif remaja sekarang, seperti dilansir dari harian merdeka.com, menunjukkan peningkatan dalam aspek kenakalan remaja. Dimana menurut Burton (2015), perilaku remaja yang seperti ini menunjukkan ciri dari selfesteem yang rendah.

Self-esteem adalah penilaian individu terhadap dirinya sendiri secara positif atau negatif yang dipengaruhi oleh hasil interaksinya dengan orang-orang yang penting di lingkungannya serta dari sikap, penerimaan, penghargaan, dan perlakuan orang lain terhadap dirinya (Haryati, 2014). Menurut Lawrence (2006), self-esteem terbagi menjadi dua bagian, yaitu global self-esteem dan spesifik self-esteem. Dimana global self-esteem 
mengacu pada perasaaan keseluruhan dari individu yaitu perasaaan berharga dan kepercayaan diri. Sementara spesifik self-esteem mengacu pada perasaan berharga dan kepercayaan diri individu pada bidang atau aktivitas tertentu. Apabila pemenuhan selfesteem siswa tidak berjalan maksimal, maka akan berdampak dalam memperendah hasrat belajar siswa, mengaburkan fokus pikiran, dan membuat siswa enggan mengambil resiko (Utari, 2007). Dilihat dari berbagai dampak negatif inilah maka dibutuhkan suatu pembelajaran yang bisa membantu siswa dalam mengembangkan self-esteemnya. Salah satu pembelajaran yang sesuai yaitu pembelajaran matematika dengan menggunakan pendekatan open-ended (Fatah, 2016).

Pendekatan open-ended menggunakan masalah terbuka dalam pembelajarannya (Becker dan Shimada, 2005). Penggunaan masalah terbuka ini menyediakan ruang bagi siswa dalam menyampaikan pendapat sesuai dengan kemampuan siswa. Apabila siswa diberikan kesempatan untuk menyelesaikan masalah sesuai dengan kapasitas kemampuan mereka, siswa tersebut akan merasa lebih dihargai (Mustikasari, Zulkardi, \& Aisyah, 2010). Dimana menurut Maslow, rasa pengakuan/penghargaan dari orang lain merupakan salah satu kebutuhan dari self-esteem (Usnaini, 2011). Selain itu, melalui pembelajaran open-ended memberikan kesempatan kepada siswa untuk berfikir secara optimal, dan berusaha menemukan jawaban dari berbagai sudut pandang (Lestari, Hartono, \& Purwoko, 2016).

Selain itu berdasarkan penelitian yang telah dilakukan oleh Fatah (2016), selfesteem siswa cukup baik pada pembelajaran matematika menggunakan pendekatan openended dibandingkan pada kelas konvensional. Berdasarkan penelitian sebelumnya ini, terlihat bahwa self-esteem siswa tergolong baik pada pembelajaran menggunakan pendekatan open-ended. Oleh sebab itu, peneliti tertarik untuk mendeskripsikan selfesteem siswa dalam pembelajaran matematika menggunakan pendekatan open-ended. Penelitian ini diharapkan mampu menjadi sumber informasi baik bagi guru maupun peneliti lainnya mengenai deskripsi self-esteem siswa dalam pembelajaran matematika menggunakan pendekatan open-ended.

\section{METODE PENELITIAN}

\section{A. Tempat dan Waktu Penelitian}

Penelitian ini merupakan penelitian deskriptif yang bertujuan untuk mendeskripsikan self-esteem siswa pada pembelajaran matematika dengan menggunakan pendekatan open- 
ended. Penelitian ini dilaksanakan pada bulan Oktober 2016, dengan subjek penelitian yaitu sebanyak 42 siswa kelas VIII.6 SMP Negeri 2 OKU.

\section{B. Tahap Pelaksanaan Penelitian}

Penelitian ini melalui tiga tahap, yaitu meliputi tahap persiapan, tahap pengimpilan data, dan tahap analisis data. Adapun rincian dari ketiga tahapan ini yaitu sebagai berikut.

\section{Tahap Persiapan}

Pada tahap ini peneliti menghubungi sekolah yang dijadikan sebagai tempat penelitian, melakukan observasi awal pada kegiatan pembelajaran di sekolah, mensosialisasikan konsep pembelajaran dan hal-hal yang berkaitan dengan penelitian di sekolah tersebut. Kemudian selanjutnya, menyusun Rencana Pelaksanaan Pembelajaran (RPP), mempersiapkan masalah open-ended yang akan digunakan dalam pembelajaran yang peneliti adopsi dari Assesment Prep for Common Core mathematics: Grade 8, dan mempersiapkan instrumen penelitian, yang terdiri dari angket Math-Spesific Self Esteem (MSSE) dan lembar observasi Metcalfe Behavioural Checklist of Self Esteem (MBCSE).

\section{Tahap Pengumpulan Data}

Pada tahap ini, peneliti melaksanakan pembelajaran matematika dengan pendekatan open-ended sesuai dengan Rencana Pelaksanaan Pembelajaran (RPP) yang telah dibuat. Selama pembelajaran berlangsung peneliti mengobservasi siswa menggunakan lembar observasi MBCSE. Pada pertemuan ketiga, peneliti memberikan angket MSSE pada siswa. Sementara wawancara dilaksanakan setelah peneliti menganalisis data angket MSSE dan lembar observasi MBCSE.

\section{Tahap Analisis Data}

Tahapan ini meliputi analisis data yang diperoleh dari penelitian, yang kemudian akan disajikan dalam hasil penelitian. Langkah-langkah penganalisisan data yaitu: memberi nilai/skor pada angket MSSE dan lembar observasi MBCSE siswa, sesuai dengan kriteria pemberian skor yang telah disiapkan peneliti sebelumnya. Setelah data diolah dan diperoleh nilainya, maka self-esteem siswa tersebut dikategorikan menjadi beberapa kategori. Kemudian data dari wawancara akan dianalisis yakni dengan tahapan transkripsi, pengkodingan, penyajian data dalam bentuk teks naratif, dan terakhir yaitu menyimpulkan data. 


\section{HASIL DAN PEMBAHASAN}

Berdasarkan data observasi yang telah dikumpulkan oleh peneliti selama proses penelitian, didapatlah beberapa kategori self-esteem siswa di kelas VIII.6. Adapun observasi dilakukan selama pertemuan pertama dan pertemuan kedua. Dalam penelitian ini, peneliti menggunakan lembar observasi MBCSE untuk mengobservasi sikap siswa selama pemebelajaran matematika menggunakan pendekatan open-ended di kelas. Tabel 1 berikut ini memperlihatkan self-esteem siswa melalui observasi selama 2 kali pertemuan.

Tabel 1. Data Observasi Self-esteem Siswa

\begin{tabular}{ccccccccc}
\hline \multirow{2}{*}{ Rentang } & \multicolumn{2}{c}{ Pertemuan 1 } & \multicolumn{2}{c}{ Pertemuan 2 } & \multicolumn{2}{c}{ Rata-rata } & \\
\cline { 2 - 7 } & $\begin{array}{c}\text { Banyak } \\
\text { Siswa }\end{array}$ & $\%$ & $\begin{array}{c}\text { Banyak } \\
\text { Siswa }\end{array}$ & $\%$ & $\begin{array}{c}\text { Banyak } \\
\text { Siswa }\end{array}$ & Kategori \\
\hline $20-34$ & 0 & 0 & 0 & 0 & 0 & 0 & $\begin{array}{c}\text { Sangat } \\
\text { Rendah }\end{array}$ \\
\hline $35-49$ & 18 & 42,9 & 13 & 31,0 & 15 & 36,9 & Rendah \\
\hline $50-64$ & 22 & 52,4 & 25 & 59,5 & 24 & 56,0 & Tinggi \\
\hline $65-80$ & 2 & 4,8 & 4 & 9,5 & 3 & 7,1 & $\begin{array}{c}\text { Sangat } \\
\text { Tinggi }\end{array}$ \\
\hline Rata-rata & 52,1 & & & 53,8 & & 52,95 & Tinggi \\
\hline
\end{tabular}

(Sumber: Data Primer, Tahun: 2016)

Berdasarkan data observasi terjadi peningkatan rata-rata self esteem siswa dari pertemuan pertama ke pertemuan kedua. Hal ini sesuai dengan yang disampaikan Shoimin (2014) bahwa pembelajaran matematika dengan menggunakan pendekatan openended memiliki kelebihan yakni siswa menjadi lebih aktif dan termotivasi dalam kegiatan pembelajaran, baik siswa berkemampuan yang rendah sekalipun. Dikarenakan siswa diberikan kesempatan untuk merespons pertanyaan sesuai dengan kapasitas mereka masing-masing. Sehingga hal inilah yang membuat siswa merasa mampu untuk mengerjakan tugas yang diberikan dan berpartisipasi dalam kegiatan pembelajaran.

Pada pertemuan pertama, secara keseluruhan siswa mengalami kesulitan dalam memahami masalah. Dikarenakan mereka belum terbiasa menghadapi bentuk soal openended. Selanjutnya, pada pertemuan kedua keseluruhan siswa sudah agak lebih memahami maksud soal, dibandingkan pada pertemuan pertama. Meskipun masih 
terdapat beberapa kesulitan dalam menyelesaikan LKS. Pada saat diskusi berlangsung, peneliti berkeliling melihat aktivitas diskusi kelompok. Disini peneliti mengamati proses interaksi antar siswa. Dalam berinteraksi, harga diri seseorang mempengaruhi bagaimana mereka berinteraksi dan menyesuaikan diri dengan lingkungannya (Widodo dan Pratitis, 2013). Siswa yang memiliki self-esteem tinggi akan puas dengan kemampuan dirinya dan memiliki penghargaan positif dari lingkungan. Sementara, siswa yang memiliki self esteem rendah akan sulit mengekspresikan dirinya. Pada proses diskusi ini, telihat perbedaan antara siswa yang memiliki self-esteem tinggi dan siswa yang memiliki selfesteem rendah. Tetapi penggunaan masalah open ended membuat siswa baik yang memiliki kemampuan rendah, mampu memberi respon sesuai dengan kemampuannya.

Siswa yang dikategorikan memiliki self-esteem sangat tinggi, dilihat selama proses pembelajaran mendominasi dalam diskusi kelompok, yaitu banyak memberikan pendapat atau masukkan untuk anggota kelompoknya. Siswa juga berani mengajukan pertanyaan/pendapat pada saat pembelajaran berlangsung. Sementara untuk siswa yang dikategorikan memiliki self-esteem tinggi tidak jauh berbeda dengan siswa yang dikategorikan memiliki self-esteem sangat tinggi. Untuk siswa yang memiliki self-esteem rendah, awalnya mereka terlihat seperti malas untuk berdiskusi dalam kelompok. Tetapi setelah guru membimbing dan mereka melihat bahwa soal pada LKS bisa dijawab sesuai dengan pemikiran mereka sendiri, beberapa siswa mulai terlihat berpikir bagaimana cara menjawab soal pada LKS tanpa perlu memikirkan rumus.

Berdasarkan data yang didapat angket MSSE, terdapat beberapa siswa yang terkategori memiliki self-esteem yang rendah. Hal ini bisa disebabkan beberapa faktor. Dilihat dari persentase kemunculan faktor dari self-esteem, faktor tersebut yakni pada faktor human influence (pengaruh individu lain) yang persentase kemunculannya terendah. Hal ini sesuai dengan apa yang disampaikan oleh Lutan (Pramesti, 2011) bahwa 3 faktor dari self-esteem melibatkan pengaruh peran dari individu lain, yaitu orang tua, teman, dan guru. Tabel 2 berikut memperlihatkan data mengenai self-esteem siswa yang diperoleh dari Angket MSSE. 
Tabel 2. Data Angket MSSE Siswa

\begin{tabular}{|c|c|c|c|}
\hline Rentang & Banyak Siswa & Persentase $(\%)$ & Kategori \\
\hline $119-146$ & 12 & 30 & Sangat Tinggi \\
\hline $91-118$ & 28 & 70 & Tinggi \\
\hline $63-90$ & 0 & 0 & Rendah \\
\hline $38-62$ & 0 & 0 & $\begin{array}{l}\text { Sangat } \\
\text { Rendah }\end{array}$ \\
\hline Rata-rata & \multicolumn{2}{|c|}{110,7} & Tinggi \\
\hline
\end{tabular}

(Sumber: Data Primer, Tahun: 2016)

Pada siswa dengan self-esteem sangat tinggi dan tinggi, siswa cenderung berani dan percaya diri pada saat mengajukan pendapat. Sedangkan, pada siswa dengan selfesteem rendah, mereka sebenernya kadang mampu untuk menjawab permasalahan. Tetapi, mereka seringkali menyimpan jawaban sendiri, sampai dihampiri oleh guru. Hal ini bisa dikarenakan, mereka terlalu memikirkan reaksi dari orang lain apabila jawaban mereka salah. Sehingga terkadang guru harus menghampiri mereka satu persatu untuk membimbing mereka dalam mengutarakan pendapat. Sikap siswa yang seperti ini mengindikasikan bahwa siswa tersebut cenderung menghindari kegagalan dan enggan untuk berubah atau mencoba sesuatu yang baru. Padahal kedua hal ini merupakan suatu proses yang berpengaruh pada self-esteem (Denis, 2006). Selain itu, sikap siswa yang seperti ini sesuai dengan karakteristik dari siswa dengan self-esteem rendah yang disampaikan oleh Utari (2007), yakni siswa dengan self-esteem rendah melakukan sesuatu hal dengan diiringi rasa takut akan penolakan, dan cenderung terlalu mengkhawatirkan pendapat dari orang lain.

Berdasarkan hasil wawancara dengan siswa, pada siswa dengan self-esteem sangat tinggi dan tinggi mengatakan bahwa minat mereka terhadap matematika, tergantung dengan mengerti atau tidaknya mereka pada materi tersebut. Hal ini sejalan dengan apa yang disampaikan oleh Lawrence (2006) bahwa pengaruh guru sangat berperan besar pada self-esteem siswa. Selain itu, individu disekitar siswa juga memiliki pengaruh pada self-esteem siswa. Apabila siswa tidak memiliki individu disekitarnya, dalam penelitian ini yaitu ketertarikan pada matematika, maka individu tidak mempunyai tempat untuk bertanya apabila tidak mengerti materi, akibatnya rasa tidak mengerti ini bisa mengurangi motivasi siswa untuk memberikan perhatian pada saat pembelajaran. Padahal motivasi menurut yang disampaikan Lawrence (2006), merupakan salah satu hal yang berpengaruh pada self-esteem. 
Berdasarkan hasil wawancara pada siswa juga, terlihat beberapa siswa yang lebih memilih untuk bekerja sendiri dibandingkan dalam kelompok. Hal ini disebabkan karena pada diskusi grup seringkali ada siswa yang terlalu mendominasi dan siswa yang terlalu mengandalkan orang lain (Beebe dan Masterson, 2015). Perbedaan ini juga disebabkan karena pada individu terdapat tipe belajar yang berbeda, ada yang lebih nyaman ketika belajar sendiri dan dalam kondisi tenang, ada pula yang lebih menyukai bertukar pikiran dan berdiskusi. Dalam pembelajaran matematika menggunakan pendekatan open-ended ini, pada tahap pertama dibentuk kelompok kecil dimana setiap individu dalam kelompok berdiskusi menuangkan idenya. Selanjutnya, tahap kedua yaitu perwakilan dari kelompok menyajikan hasil diskusi serta membahas permasalahan tersebut dengan seluruh kelompok di kelas.

Selain itu, dari hasil wawancara menunjukkan bahwa siswa dengan self-esteem sangat tinggi dan tinggi, memiliki sikap yakni mampu bekerja secara mandiri dan tidak segan dalam membantu orang lain. Dimana hal ini merupakan ciri-ciri dari siswa dengan self-esteem tinggi seperti yang disampaikan oleh Child Development Institute. Sementara berdasarkan wawancara pada siswa dengan self-esteem rendah, siswa tersebut menunjukkan ciri dari self-esteem rendah yakni masih enggan atau takut dalam memperlihatkan kemampuan yang ada pada dirinya.

Dilihat dari data MBCSE, kategori tingkat self-esteem siswa secara umum tergolong tinggi pada pembelajaran matematika menggunakan pendekatan open ended. Begitupun berdasarkan data MSSE, kategori tingkat self-esteem siswa secara umum tergolong tinggi juga pada pembelajaran matematika menggunakan pendekatan open ended. Secara keseluruhan ini berarti pada pembelajaran matematika menggunakan pendekatan open-ended, self-esteem matematika siswa tergolong tinggi. Hal ini sesuai dengan hasil penelitian Fatah (2016) yang mengatakan bahwa pencapaian self-esteem siswa terkategori baik dalam pembelajaran dengan pendekatan open-ended.

\section{KESIMPULAN DAN SARAN}

\section{A. Kesimpulan}

Berdasarkan hasil penelitian di kelas VIII.6 SMP Negeri 2 OKU, self-esteem siswa dalam pembelajaran matematika menggunakan pendekatan open-ended adalah tinggi. Hal ini dilihat dari hasil perolehan angket MSSE dan lembar observasi MBCSE, yaitu dengan rincian data sebagai berikut: dari data lembar observasi MBCSE persentase siswa yang 
memiliki self-esteem dengan kategori sangat tinggi adalah 7,1\%. Selanjutnya 56\% siswa dengan kategori self-esteem tinggi; 36,9\% siswa dengan kategori self-esteem rendah. Sementara, berdasarkan data angket MSSE persentase siswa dengan kategori self-esteem sangat tinggi adalah 30\% dan $70 \%$ siswa dengan kategori self-esteem tinggi.

\section{B. Saran}

Dari hasil penelitian yang diperoleh, maka peneliti menyarankan kepada (1) Guru, agar diharapkan mampu melaksanakan pembelajaran matematika menggunakan pendekatan open-ended yang dapat membantu siswa dalam mengembangkan selfesteemnya. Selanjutnya yaitu kepada (2) peneliti, diharapkan mengadakan penelitian lanjutan mengenai self-esteem, yaitu mengenai bagaimana self-esteem siswa dalam metode pembelajaran yang lain dalam pembelajaran matematika.

\section{DAFTAR PUSTAKA}

Andriansyah, M. (2016). Kenakalan Remaja Meningkat, Rumah 'Hantu' jadi Tempat Kongkow. Tersedia Online : https://www.merdeka.com/peristiwa/kenakalan-remaja- meningkat- rumahhantu- jadi-tempat-kongkow.html diakses pada 25 November 2016.

Arifin, Z. (2012). Evaluasi Pembelajaran. Jakarta: Direktorat Jenderal Pendidikan Agama Islam Kementerian Agama.

Beebe, S.A., dan Masterson, J.T. (2015). Communicating in Small Group: Principles and Practices Eleventh Edition. Boston: Pearson Education, Inc.

Becker, J. P., dan Shimada, S. (2005). The Open-Ended Approach: A New Proposal for Teaching Mathematics. United States of America: The National Council of Teachers of Mathematics.

Burton, N. (2015). Self-Confidence Versus Self-Esteem. Tersedia Online : https://www.psychologytoday.com/blog/hide-and-seek/201510/selfconfidence-versus- $\quad$ self-esteem diakses pada 20 Agustus 2016.

Fatah, dkk. (2016). Open Ended Approach: An Effort in Cultivating Students' Mathematical Creative Thinking Ability and Self-Esteem in Mathematics. Journal on Mathematics Education Volume 7, No. 1, January 2016, pp. 918.

Haryati, S. (2014). Hubungan Harga Diri dan Interaksi Teman Sebaya dengan Kepercayaan Diri Remaja Awal. Tesis. Surakarta : Universitas Muhammadiyah Surakarta.

Lawrence, D. (2006). Enhancing Self-esteem in the classroom: 3rd Edition. London: Paul Chapman Publishing.

Lestari, N., Hartono, Y., \& Purwoko. (2016). Pengaruh Pendekatan Open-ended Terhadap Penalaran Siswa Sekolah Menengah Pertama Palembang. Jurnal Pendidikan Matematika Vo.10 No.1, 81-97. 
Metcalfe, R. D. (1997). A Behavioural Checklist for The Measurement of Self- Esteem in The Classroom. Edith Cowan University.

Mustikasari, Zulkardi, dan Aisyah, N. (2010). Pengembangan Soal-soal Open- ended Pokok Bahasan Bilangan Pecahan di Sekolah Menengah Pertama. Jurnal Pendidikan Matematika, Volume 4. NO.1 , 45-60.

Pramesti, A. (2015). Hubungan antara Self Esteem terhadap Prestasi Belajar Mata Pelajaran Makanan Kontinential pada Siswa Jurusan Tata Boga Konsentrasi Jasa Boga SMK Negeri 1 Sewon. Skripsi. Yogyakarta : Universitas Negeri Yogyakarta.

Randall, V.R. (2011). Learning Domains or Bloom's Taxonomy. Tersedia Online : http://academic.udayton.edu/health/syllabi/health/Unit01/lesson01b.htm diakses pada 13 Agustus 2016.

Reyna, B.S. (2000). Determining Positive Indicators of Math-Spesific Self Esteem in Hispanic Students. Disertasi. Texas : Texas Tech University.

Shoimin, A. (2014). 68 Model Pembelajaran inovatif dalam Kurikulum 2013. Yogyakarta: Ar-ruzz Media.

Usnaini, A. (2011). Efektivitas Teknik Thought Stopping dalam Meningkatkan Harga

Diri Siswa VIII H di Madrasah Tsanawiyah Negeri Mojosari. Skripsi.

Surabaya: UIN Sunan Ampel Surabaya.

Utari, R. (2007). Upaya Sekolah dalam Pembentukan Self-esteem Siswa melalui Pembelajaran. Jurnal Dinamika Pendidikan No. 1: 76-89.

Widodo, A. S., dan Pratitis, N. T. (2013). Harga Diri Dan Interaksi Sosial Ditinjau Dari Status Sosial Ekonomi Orang Tua. Persona Vol.2, No.2, 131-138. 